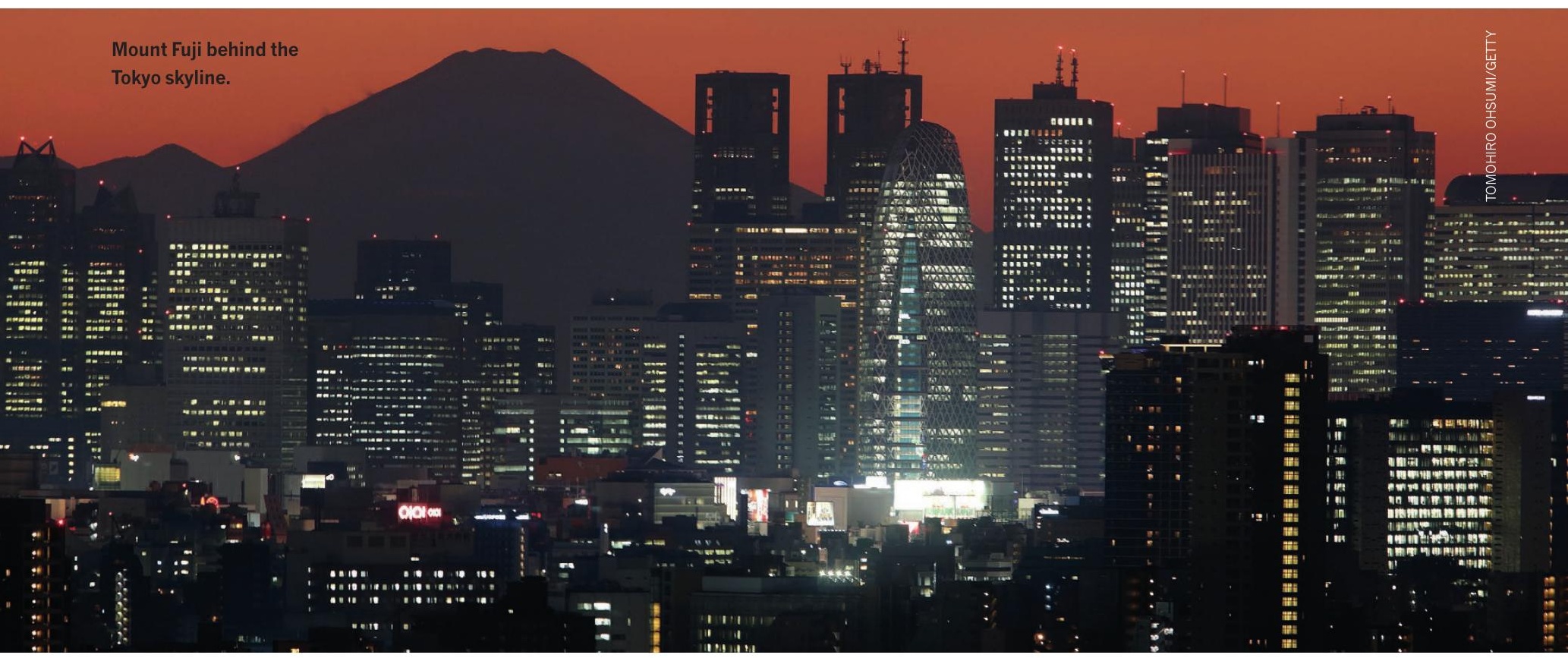

\title{
STRIVING FOR A RESEARCH RENAISSANCE
}

$\mathrm{T}$ 1 his Nature Index issue looks closely at Japan's recent research performance. Despite being among the top science nations, its publication output has stalled over the past decade.

Japan's loosening grip on global science has been more pronounced than other research powerhouses. China's science output, in particular, has grown dramatically. Chinese papers in the Web of Science (WoS) grew by nearly $300 \%$ between 2005 and 2015, and by almost $180 \%$ in the larger Scopus database. In 2015, almost one in five papers in WoS came from China, compared to about one in 10 papers a decade earlier.

China's rapid growth has meant that Japan is losing its share of the world's science output, along with other countries whose output is growing less spectacularly, such as the United States and the United Kingdom.

While the decline of the US and the UK is only relative to China's output, Japan's has also fallen in absolute terms. Japanese researchers published about 600 fewer papers in WoS in 2015 than in 2005. While the decrease is less than $1 \%$, the country's share of the world's articles dropped from $8.4 \%$ to $5.2 \%$. Data from the Nature Index also shows a decline of $19.6 \%$ in Japan's contribution between 2012 and 2016.
Understandably this lull worries Japanese academics, research administrators, policymakers and ministers. Because of Japan's long period of economic stagnation, government spending on science has remained flat since 2001. A significant portion of this funding is also now steered towards specific initiatives designed to boost the international standing of the country's top research universities.

To reviltalize research, Japan's government has introduced a range of policies designed to recruit top international researchers. These measures, however, have yet to have a noticeable effect. Meanwhile, early-career scientists have fewer opportunities for permanent jobs - a trend we explore on page $\mathrm{S} 10$.

Despite these woes, Japan remains among the world's scientific leaders. The country ranked fifth in the Nature Index in 2016, based on its contribution to high-quality science.

Japanese research is at a tipping point. If it cannot boost its output in the next decade, and nurture its high-quality science, the country risks losing its status as one the world's top research nations.

\section{Nicky Phillips \\ Editor, Nature Index}

EDITORIAL: Stephen Pincock, Nicky Phillips, Rebecca Dargie, Herb Brody, Vicki Kitchener, Ichiko Fuyuno, Ian Munroe, Tim Hornyak, Flynn Murphy, Linda Nordling. ANALYSIS: Larissa Kogleck, Aaron Ballagh. ART \& DESIGN: Alisdair Macdonald, Kate Duncan, Chris Gilloch, Chika Takeda. WEB \& DESIGN: Bob Edenbach, Olivier Lechevalier, Naomi Nakahara, Pamela Sia, Bart Riepe, Jörn Ishikawa, Yuxin Wang, Jennie Pao, Paul Glaeser. PRODUCTION: Sue Gray, Karl Smart, Ian Pope, Matt Carey, Ali Mosud, Elizabeth Campbell. MARKETING: Alan Abery. PROJECT MANAGEMENT: Anastasia Panoutsou, Rebecca Jones, Yuko Onishi. SALES: Yuki Fujiwara, Maki Ishikawa, Yuko Takai. ART DIRECTOR: Kelly Buckheit Krause. PUBLISHING: Nick Campbell, Richard Hughes, David Swinbanks.

NATURE INDEX 2017 JAPAN

Nature Index 2017 Japan, a supplement to Nature, is produced by Nature Research, the flagship science portfolio of Springer Nature. This publication is based on data from the Nature Index, a Nature Research website maintained and made freely available at natureindex.com.

NATURE EDITORIAL OFFICES The Campus, 4 Crinan Street, London N1 9XW, UK Tel: +44 (0)20 78334000 Fax: +44 (0)20 7843 4596/7

CUSTOMER SERVICES To advertise with the Nature Index, please visit natureindex.com/client-services feedback@nature.com Copyright @ 2017 Macmillan Publishers Limited, part of Springer Nature. All rights reserved. 